\title{
Autologous Mesothelin-specific Human mRNA CAR-transfected PBMCs MCY-M11
}

National Cancer Institute

\section{Source}

National Cancer Institute. Autologous Mesothelin-specific Human mRNA CARtransfected PBMCS MCY-M11. NCI Thesaurus. Code C155775.

Autologous peripheral blood mononuclear cells (PBMCs) transfected with antimesothelin chimeric antigen receptor (CAR) mRNA, with potential antineoplastic activity. Upon intraperitoneal (IP) administration, the autologous mesothelin-specific human mRNA CAR-transfected PBMCs MCY-M11 recognize, bind to, phagocytose and directly kill cancer cells expressing mesothelin. In addition, MCY-M11 stimulates the immune system to induce a cytotoxic T-lymphocyte response against the mesothelin-expressing cancer cells. Mesothelin, a cell surface glycoprotein involved in cell adhesion, is overexpressed in many epithelial-derived cancers. 